\title{
Rigid bronchoscopy-induced bacterial translocation: is it a real threat?
}

\section{To the Editor:}

I read with great interest the report by NAYCI et al. [1], regarding rigid bronchoscopy-induced bacterial translocation in rats. However, several of their speculative comments are misleading and merit comment.

First, the animal model used in their study does not completely reproduce all the features of rigid bronchoscopy in humans. Bronchoscopy means examination of the tracheobronchial tree through a bronchoscope. In the current study, the inserted angiocath did not have similar physical properties of a rigid bronchoscope. Furthermore, this examination was performed outside the tracheobronchial tree through a lateral neck incision. For this reason, it would be better to entitle the article "intratracheal insertion of an angiocath induces bacterial translocation" rather than "rigid bronchoscopy induces bacterial translocation".

Secondly, the authors found a decrease in $\mathrm{pH}$ and arterial oxygen tension $\left(\mathrm{Pa}, \mathrm{O}_{2}\right)$, and an increase in arterial carbon dioxide tension values following insertion of the angiocath. They have concluded that bacterial translocation may be related to the hypoxaemia-induced mucosal damage of the intestines. However, SAARnIVAARA et al. [2] have found that instrumentation with a telescope during rigid bronchoscopy ameliorates rather than impairs the ventilation and oxygenation of the patients. During the course of the bronchoscopy, as well as after $1 \mathrm{~h}$ in the recovery room, the arterial acid-base status was within normal limits; the mean $\mathrm{Pa}, \mathrm{O}_{2}$ value during bronchoscopy ranged $23-32 \mathrm{kPa}(175-240 \mathrm{mmHg})$ and was $18 \mathrm{kPa}(138 \mathrm{mmHg})$ in the recovery room when the patients breathed $\sim 35 \%$ oxygen in the air. The authors suggested that the increased $\mathrm{Pa}, \mathrm{O}_{2}$ value might be the result of increased oxygen concentration as well as of an increased inflation pressure at the distal end of the bronchoscope [2]. Furthermore, it has been suggested that the term rigid bronchoscopy should be replaced with "open ventilating bronchoscopy", because the property of splinting open the airway and providing a side-arm for delivery of oxygen or anesthetic gases is an inherent feature of all present rigid bronchoscopes. In contrast, the flexible bronchofibrescope inevitably fills a portion of the airway and diminishes ventilation [3]. These findings suggest that rigid bronchoscopy is a safe procedure regarding hypoxaemia.

Thirdly, what was the average internal tracheal diameter of the rats? This is an important point, since if the diameter of an angiocath is close to the tracheal diameter of a rat this may lead to a much tighter insertion and the latter situation may cause tracheal mucosal damage during the procedure. According to the authors, mucosal damage induced by the bronchoscope can promote bacteraemia and bacterial translocation. Nevertheless, in my opinion, the risk of mucosal damage is minimal for a human trachea during procedure performed by a well-trained and skilled bronchoscopist, because anteroposterior and transverse internal diameters of the adult human trachea are $16 \times 14 \mathrm{~mm}$, and the rigid bronchoscopes commonly used have an external diameter that varies $2-9 \mathrm{~mm}[4,5]$.

In summary, one should be cautious of making a conclusion about a direct link between rigid bronchoscopy and bacterial translocation, because the results obtained using this animal model may be significantly different than those obtained in clinical studies.

\section{A. Zamani \\ Dept of Chest Diseases, Meram Medical Faculty, Selçuk University, Konya, Turkey.}

\section{References}

1. Nayci A, Atis S, Talas DU, Ersoz G. Rigid bronchoscopy induces bacterial translocation: an experimental study in rats. Eur Respir $J$ 2003; 21: 749-752.

2. Saarnivaara L, Tarkkanen J. The effect of instrumentation with a telescope during bronchoscopy on arterial oxygen tension and acid-base balance. Acta Anaesthesiol Scand 1983; 27: $242-244$

3. Helmers RA, Sanderson DR. Rigid bronchoscopy: the forgotten art. Clin Chest Med 1995; 16: 393-399.

4. Scothorne RJ. The respiratory system. In: Romanes GJ, ed. Cunningham's textbook of anatomy. New York, Oxford University Press, 1995; pp. 491-529.

5. Prakash UBS, Diaz-Jimenez JP. The rigid bronchoscope. In: Prakash UBS, ed. Bronchoscopy. Philadelphia, LippincottRaven, 1997; pp. 53-69.

\section{From the authors:}

We would like to thank A. Zamani for his comments concerning our article [1].

It seems that our methodology regarding the bronchoscopic procedure has been misunderstood. We intended to develop a bronchoscopic instrument that was basically a rigid, straight and hollow metallic tube, and followed the main bronchoscopic procedures. The instrument was connected to a threeway stopcock. An open system, one opening was then connected to the oxygen source, while the other accessed the atmosphere. The latter orifice precluded any unforeseen risk of excessive airway pressure and allowed to aspirate tracheobronchial secretion. The bronchoscopic instrument was inserted into the rat airway via the transoral route, certainly not outside the tracheobronchial tree. The lateral neck incision was performed to confirm whether the bronchoscopic instrument was in the trachea.

During the planning phase of this project, the upper airway anatomy, the trachea and the main stem bronchi of the rat had been carefully examined to construct our experimental design thoroughly. Meticulous dissection provided an excellent view of the anatomic structures of the airway. The length of the bronchoscope was $70 \mathrm{~mm}$ and the external diameter was $3 \mathrm{~mm}$. The length of the bronchoscope was sufficient to reach the lower trachea and main stem bronchi. The bronchoscope was marked every $1 \mathrm{~cm}$ to estimate the anatomic localisation of the tip of the bronchoscope. The bronchoscope was inserted into the rat airway via the transoral route. The distance from the mouth to the epiglottis was approximately $30-32 \mathrm{~mm}$. The larynx began at the opening bounded 